University of Nebraska - Lincoln

DigitalCommons@University of Nebraska - Lincoln

Sociology Department, Faculty Publications

Sociology, Department of

2015

\title{
Prevalence and Correlates of Physical Dating Violence Among North American Indigenous Adolescents
}

\author{
Dane Hautala \\ University of Nebraska-Lincoln, dane.hautala@huskers.unl.edu \\ Kelley J. Sittner Hartshorn \\ University of Nebraska-Lincoln, kelley.sittner@okstate.edu \\ Brian E. Armenta \\ University of Nebraska-Lincoln, berikarmenta@gmail.com \\ Les B. Whitbeck \\ University of Nebraska-Lincoln, Iwhitbeck2@unl.edu
}

Follow this and additional works at: https://digitalcommons.unl.edu/sociologyfacpub

Part of the Demography, Population, and Ecology Commons, Family, Life Course, and Society Commons, Gender and Sexuality Commons, Inequality and Stratification Commons, Place and Environment Commons, Race and Ethnicity Commons, and the Social Psychology and Interaction Commons

Hautala, Dane; Sittner Hartshorn, Kelley J.; Armenta, Brian E.; and Whitbeck, Les B., "Prevalence and Correlates of Physical Dating Violence Among North American Indigenous Adolescents" (2015). Sociology Department, Faculty Publications. 270. https://digitalcommons.unl.edu/sociologyfacpub/270

This Article is brought to you for free and open access by the Sociology, Department of at DigitalCommons@University of Nebraska - Lincoln. It has been accepted for inclusion in Sociology Department, Faculty Publications by an authorized administrator of DigitalCommons@University of Nebraska - Lincoln. 
Published in Youth \& Society (2015), 23 pp.

doi: 10.1177/0044118X14559503

Copyright (C) 2014 Dane S. Hautala, Kelley J. Sittner Hartshorn,

Brian Armenta, and Les Whitbeck. Published by SAGE Publications.

Used by permission.

Published online November 25, 2014.

\title{
Prevalence and Correlates of Physical Dating Violence Among North American Indigenous Adolescents
}

\author{
Dane S. Hautala, ${ }^{1}$ Kelley J. Sittner Hartshorn, ${ }^{2}$ \\ Brian Armenta, ${ }^{1}$ and Les Whitbeck ${ }^{1}$
}

\author{
1 University of Nebraska-Lincoln, USA \\ 2 Oklahoma State University, Stillwater, USA \\ Corresponding author - Dane S. Hautala, Department of Sociology, \\ University of Nebraska-Lincoln, 204 Benton Hall, Lincoln, NE 68588, USA; \\ email dane.hautala@huskers.unl.edu
}

\begin{abstract}
This study examined the lifetime prevalence of physical dating violence, including victimization, perpetration, and the overlap between the two (mutual violence), among a population sample of 551 reservation/reserve residing Indigenous (i.e., American Indian and Canadian First Nations) adolescents in the upper-Midwest of the United States and Canada. Potential correlates of four dating violence profiles (i.e., no dating violence, perpetration only, victimization only, and mutual violence) relevant to this population also were considered. The clearest pattern to emerge from multinomial logistic regression analyses suggested that adolescents who engage in problem behaviors, exhibit high levels of anger, and perceive high levels of discrimination have increased odds of lifetime mutual dating violence relative to those reporting no dating violence. Furthermore, gender comparisons indicated that females were more likely to report being perpetrators only, whereas males were more likely to report being victims only. Considerations of dating violence profiles and culturally relevant prevention strategies are discussed.
\end{abstract}

Keywords: American Indian, First Nations, dating violence, correlates, discrimination 
$\mathrm{O}$ ver the past two decades, physical dating violence has received considerable attention from public health officials and scholars who study adolescence. Findings from large school-based samples indicate that approximately one in three adolescents has been the victim of physical dating violence (Foshee, 1996; Molidor \& Tolman, 1998; O'Leary, Smith Slep, Avery-Leaf, \& Cascardi, 2008) and approximately one in four has perpetrated physical dating violence (Foshee, 1996; Malik, Sorenson, \& Aneshensel, 1997; O'Leary et al., 2008). Moreover, recent work has identified a significant overlap in victimization and perpetration (Chiodo et al., 2012; Giordano, Soto, Manning, \& Longmore, 2010; Gray \& Foshee, 1997; O'Leary et al., 2008; Orpinas, Hsieh, Song, Holland, \& Nahapetyan, 2013; Swahn, Alemdar, \& Whitaker, 2010), with those who report mutual violence (both victimization and perpetration) also reporting more frequent and severe violence compared with relationships with victimization or perpetration only. Most of these studies descriptively establish the overlap between perpetration and victimization but few studies examine potential correlates of dating violence profiles among adolescents (i.e., no dating violence, perpetration only, victimization only, and mutual violence; Chiodo et al., 2012).

Despite these recent advances in the literature, very little is known about dating violence among Indigenous (i.e., American Indian and Canadian First Nations) adolescents. Of the available studies, only physical dating violence victimization has been assessed, and prevalence rates vary widely. For example, Ackard and Neumark-Sztainer (2002) found that approximately 7\% of Indigenous adolescents attending Minnesota high schools reported ever being the victim of violence on a date. Youth Behavior Risk Surveillance survey data indicate that from $12 \%$ in a national sample (Pavkov, Travis, Fox, King, $\&$ Cross, 2010) to $17 \%$ of urban Indigenous adolescents (Rutman, Park, Castor, Taualii, \& Forquera, 2008) reported past-year dating violence victimization. We could locate no study that examined physical dating violence perpetration among this population.

Indigenous adolescents develop within a unique socio-cultural context which is shaped by a legacy of historical cultural losses and socio-economic disadvantage (Whitbeck, Sittner Hartshorn, \& Walls, 2014). This context, in turn, shapes exposure to a wide range of proximal factors such as substance use, delinquent behavior, mental health problems, and discrimination. This legacy of historical cultural losses and contemporary socio-economic disadvantage may play a key role in the significantly elevated rates of intimate partner violence among the adult Indigenous population in the United States (Tjaden \& Thoennes, 2000) and Canada (Perreault, 2011). Because prior research shows 
a clear link between physical dating violence in adolescence and intimate partner violence in adulthood (Cui, Ueno, Gordon, \& Fincham, 2013), a more detailed understanding of dating violence among Indigenous youth is needed to identify those who are most at risk and to inform long-term prevention and intervention efforts.

The purpose of the following study is twofold. First, we examine the lifetime prevalence of physical dating violence perpetration, victimization, and their overlap among a large sample of reservation/reserve residing Indigenous youth (ages 15-19) living in the upper-Midwest of the United States and Canada. Second, we examine problem behavior, negative emotionality, psychosocial stress, and socio-demographic correlates of four dating violence profiles (i.e., no dating violence, perpetration only, victimization only, and mutual violence), rather than perpetration and victimization in isolation. The correlates were selected based on their theoretical and empirical relevance, as well as whether they are believed to disproportionately affect Indigenous youth, compared with other racial and ethnic groups.

\section{Literature Review}

\section{Correlates of Dating Violence}

Problem behaviors. Problem behavior theory (Jessor \& Jessor, 1977) posits that deviant behaviors tend to cluster together such that adolescents who engage in any given problematic behavior (e.g., substance use) are likely to engage in other problem behaviors as well (e.g., delinquency). In this sense, dating violence perpetration can be considered part of a more general cluster of problem behaviors. Conversely, adolescents who engage in multiple problem behaviors may find themselves in the presence of risk-taking adolescents and situations that are conductive to dating violence victimization (Gover, 2004). Adolescents are likely to choose dating partners with similar characteristics to their own (Rhule-Louie \& McMahon, 2007); thus, the overlap in perpetration and victimization (mutual violence) may be a result of assortative dating processes, whereby adolescents who engage in problem behaviors select partners who engage in similar behaviors. In the present article, we focus on several problem behavior correlates that have been shown to be salient among Indigenous adolescents.

First, substance use behaviors are an important proximal risk factor for physical dating violence. For example, alcohol use has been shown to increase the odds of dating violence victimization (Malik et al., 1997; Swahn, Bossarte, \& 
Sullivent, 2006) and perpetration (Temple, Shorey, Fite, Stuart, \& Le, 2013). Marijuana use has also been associated with an increased risk of perpetration (Foshee, McNaughton Reyes, \& Ennett, 2010) and victimization (Gover, 2004), as well as the overlap between the two (Reingle, Staras, Jennings, Branchini, \& Maldonado-Molina, 2012). This risk factor may be especially important for Indigenous adolescents, who show higher rates of and more frequent alcohol and marijuana use, compared with members of other racial and ethnic groups (Wallace et al., 2002).

Second, having multiple sex partners is a significant correlate of increased dating violence victimization (Gover, 2004; Valois, Oeltmann, Waller, \& Hussey, 1999) and perpetration (Cleveland, Herrera, \& Stuewig, 2003; O'Donnell et al., 2006). Moreover, Chiodo et al. (2012) found that ever having sexual intercourse was associated with mutual dating violence. Prior evidence from national Youth Behavior Risk Surveillance data suggest that Indigenous youth are more likely to initiate sexual intercourse at earlier ages (Pavkov et al., 2010) and report more lifetime and past month sexual partners than are White youth (Rutman et al., 2008). Given these findings, we consider the number of past-year sex partners to be a potentially relevant correlate of dating violence among Indigenous youth.

Third, a number of other delinquent behaviors have been identified as potential correlates of dating violence. Prior research suggests that dating violence perpetration may be part of a more general antisocial cluster of behaviors such as delinquency (Capaldi, Dishion, Stoolmiller, \& Yoerger, 2001; Gorman-Smith, Tolan, Sheidow, \& Henry, 2001). Engaging in delinquent behavior also has been linked to increased risk of dating violence victimization (Woodward, Fergusson, \& Horwood, 2002) and the overlap in perpetration and victimization (Chiodo et al., 2012). Delinquent behaviors may be particularly relevant for Indigenous youth. For example, multiple studies (e.g., McNulty \& Bellair, 2003; Pavkov et al., 2010) show that Indigenous adolescents are disproportionately involved in violent delinquency compared with Whites and Asians.

Fourth, associating with delinquent peers can reinforce problem behaviors and dating violence perpetration (Capaldi et al., 2001). This association also may increase the risk of dating violence victimization by exposing individuals to higher risk situations. Indeed, Howard, Qiu, and Boekeloo (2003) found that associating with peers who drink and being in social situations where risky behavior is likely to occur increase the odds of dating violence victimization. The rural context of the reservation/reserve is likely to shape the size, density, and composition of peer networks (Whitbeck et al., 2014). For example, reservation/reserve-based Indigenous adolescents are likely to grow up in small peer 
cohorts lasting from childhood through adulthood. Antisocial peer groups, then, may be a salient correlate of dating violence among this population.

Negative emotionality. In addition to the problem behavior correlates, negative emotions such as anger may be a factor conducive to aggression within relationship dyads (e.g., Dodge, Price, Coie, \& Christopoulos, 1990; Wekerle \& Wolfe, 1999). Romantic relationship dyads composed of individuals with an angry temperament are likely to interpret each other's intentions as hostile and react aggressively. This, in turn, may set off aggressive interactional patterns that can potentiate mutual dating violence (Wekerle \& Wolfe, 1999). We focus on anger temperament as a possible correlate of dating violence.

Several studies have found anger expression styles (e.g., ability to selfregulate anger) to be associated with increased physical dating violence perpetration (Clarey, Hokoda, \& Ulloa, 2010; Wolf and Foshee, 2003). Foshee, Linder, MacDougall, and Bangdiwala (2001) found aggressive responses to anger predicted onset of and chronic victimization for males. Anger has been linked with increased aggressive (Sittner Hartshorn, Whitbeck, \& Hoyt, 2012) and victimizing behaviors (e.g., bullying; Melander, Sittner Hartshorn, \& Whitbeck, 2013) among Indigenous youth. As such, we expect anger to be a relevant correlate of dating violence.

Psychosocial stress. There is ample evidence for the problem behavior and negative emotionality correlates reviewed above; however, little is known about the association between stressors such as perceived racial discrimination and physical dating violence. Perceived discrimination has been found to be a highly prevalent and pernicious stressor among racial and ethnic minorities in general (see Priest et al., 2013 for review) and Indigenous youth specifically (Whitbeck et al., 2014). Furthermore, perceived racial discrimination has been found to be a robust predictor of multiple health risk behaviors among Indigenous youth such as alcohol use (Cheadle \& Whitbeck, 2011), marijuana use (Cheadle \& Sittner Hartshorn, 2012), anger, and aggressive delinquency (Sittner Hartshorn et al., 2012). Stressors high in magnitude and those perceived as unjust are likely to lead to negative affective responses, which in turn, may increase aggressive propensities (Agnew, 2001) and/or limit one's awareness of potentially dangerous situations conductive to victimization (Sanderson, Coker, Roberts, Tortolero, \& Reininger, 2004).

Research is just starting to emerge on perceived discrimination as a correlate of dating violence. Most of these studies focus on African American and Latino samples. This small body of research suggests that perceived discrimination is associated with increased physical dating violence perpetration (Reed 
et al., 2010; Stueve \& O'Donnell, 2008) and victimization (Sanderson et al., 2004; Stueve \& O'Donnell, 2008; Tobler et al., 2013). Given this evidence, and prior research on health risk behaviors among Indigenous youth, we believe that perceived racial discrimination may be a salient and overlooked correlate.

Socio-demographic correlates. A large body of research suggests that adolescent females are more likely to perpetrate dating violence and that males are more likely to report being victimized (Foshee, 1996; Giordano et al., 2010; O'Leary et al., 2008). In addition to gender, dating violence prevalence increases with age (Orpinas et al., 2013), which is likely due to increased opportunity and exposure to potentially risky dating situations. Moreover, several of the aforementioned correlates of dating violence may be agegraded with increasing prevalence in later adolescence (e.g., substance use) or decreasing prevalence into early adulthood (e.g., delinquent behavior).

\section{The Present Study}

The extant literature shows a clear overlap in perpetration and victimization, along with a shared set of correlates. As such, examining dating violence profiles, rather than perpetration and victimization in isolation, is advantageous as it provides a more holistic understanding of adolescent dating violence. Given the lack of research among Indigenous youth, this approach allows us to gain a descriptive profile of dating violence among this population. To this end, we first examine the prevalence of both dating violence perpetration and victimization and the overlap between the two (mutual violence) among a sample of reservation/reserve residing Indigenous youth in the upper-Midwest of the United States and Canada. Furthermore, we investigate the overall perpetration and victimization frequencies by dating violence profile type (i.e., perpetration only vs. mutual violence, victimization only vs. mutual violence). We hypothesize that those reporting mutual violence will also report more frequent dating violence perpetration and victimization than adolescents reporting perpetration or victimization only.

Second, we examine possible correlates of dating violence profiles that are believed to be relevant for Indigenous youth. Five problem behavior indicators, which include drinking frequency, marijuana usage, number of sexual partners, delinquency, and peer delinquency, along with an overall problem behavior construct, were examined. We hypothesize that those engaging in more problematic behaviors will have higher odds of perpetration only, victimization only, and mutual violence, versus to no dating violence. Similarly, we hypothesize that anger and perceived discrimination will increase the odds of perpetration 
only, victimization only, and mutual violence, relative to no dating violence. We also predict that females will have higher odds of being perpetrators only, whereas males will have higher odds of being victims only.

\section{Method}

\section{Sample}

The data for the present article were drawn from an eight-wave longitudinal study that was designed in partnership with four U.S. American Indian reservations and four Canadian First Nations reserves (for full details, see Whitbeck et al., 2014). Although participants were recruited from different sites, all participants are members of the same cultural group and share a common cultural tradition and language with only minor variations in dialects. As part of confidentiality agreements, the names of the cultural group and reservations/reserves are not provided, nor are any attempts made to make comparisons across the study locations. At each site, Tribal Council- appointed advisory boards were responsible for handling personnel difficulties, advising the research team on questionnaire development, and reviewing and approving reports and presentation proposals. All participating staff on the reservations/ reserves (e.g., interviewers, site coordinators) were approved by the advisory boards and were either enrolled tribal members or spouses of enrollees. Interviewers for this project were trained concerning methodological guidelines of personal interviewing and all were certified for work with human subjects.

At the beginning of the study, each community provided us with a list of families of tribally enrolled children aged 10 to 12 years who lived on or proximate to (within 50 miles) the reservation/reserve. We attempted to contact all families with a target child within the specified age range to achieve a population sample. Families for this study were recruited through personal interviewer visits during which they were presented a traditional gift, an overview of the project, and an invitation to participate. Families were chosen for visits if at least one child in the house was between the ages of 10 and 12 years and was tribally enrolled. For those families who agreed to participate, both the study adolescent and one adult caretaker (and in some cases, two adults) were given US $\$ 20$ on completion of the interviews. Recruitment and incentive procedures were approved both by community-based advisory boards and the university's Institutional Review Board.

We relied on data collected during the seventh year of the study, which is when the measure of dating violence was first administered. Because we assessed lifetime rates of dating violence, we chose to examine correlates that were 
also measured in the seventh year of the study. Using previous waves would require us to use data collected two years prior, and still does not address the potential temporal ordering issue. One tribal advisory board for this study was no longer meeting; thus, data from only seven of the eight original reservations/reserves are included in this article (to respect their right to review and approve manuscripts). Fifteen adolescents (2.6\%) had missing data on one or more of the items of interest and were not included in the analyses. Complete data were available from 551 participants, representing $96.8 \%$ of those interviewed at Wave 7 (81.7\% of the original Wave 1 sample). Participants were ages 15 to 19 years $(M=17.24, S D=.88)$, and the sample was approximately evenly split by gender (48.9\% male; $51.3 \%$ female). A small portion of adolescents $(17.3 \%)$ were living off of the reservation/ reserve, but within 50 miles of it. Fewer participants (9.8\%) were living in a remote community, defined as not accessible by road at all times of the year and at a prohibitive distance from a large population center. The average per capita family income was US\$6,894 ( $S D=$ US $\$ 5,714)$, and one third $(31.4 \%)$ of the caretakers reported that their highest level of education is a high school diploma or less.

\section{Measures}

Dating violence. Dating violence was assessed using 12 adapted items from the Safe Dates Physical Violence scales, which were designed for use with adolescents (Foshee, 1996). Respondents were asked in separate self-reported questionnaires whether they had ever engaged in 12 behaviors indicative of physical dating violence perpetration, or had been the victim of such behaviors (i.e., slapped; physically twisted arm; slammed or held against a wall; kicked, choked, pushed, grabbed, or shoved; threw something; burned; hit with a fist; hit with hard object; beat up; assaulted with gun or knife). In both sets of questions, respondents were asked to report incidents that were not done in selfdefense. Response options ranged from (0) never to (3) 5 or more times. The 12 perpetration items were summed together to create an overall dating violence frequency score $(\alpha=.82)$, and then dichotomized such that those reporting no dating violence perpetration were coded as 0 and those reporting any lifetime dating violence perpetration were coded as 1 . This same strategy was used to create a variable for lifetime dating violence victimization frequency ( $\alpha$ $=.89$ ) and an ever experiencing dating violence victimization variable. Based on the dichotomous perpetration and victimization items, respondents were categorized into four mutually exclusive dating violence profiles: (a) no dating violence, (b) perpetration only, (c) victimization only, and (d) mutual violence (i.e., both perpetration and victimization). We use the continuous dating violence 
scales to examine whether those who report mutual violence also report more frequent victimization and perpetration than those who report victimization only or perpetration only. To group respondents into dating violence profiles, using the dichotomous items was necessary.

Problem behaviors. Five problem behaviors were examined. First, respondents were asked a series of questions regarding lifetime and past-year alcohol use. Participants were asked whether they had ever had more than a sip of beer, wine, and/or any other kind of alcoholic beverage, and whether they have consumed alcohol in the past 12 months. For those reporting past 12 month drinking, drinking frequency was examined with a subsequent question which asked how often participants drank in the past year. Response options ranged from (1) 1 or 2 times to (6) every day. Respondents who reported no lifetime or past-year alcohol consumption were coded as 0 .

Second, respondents were asked if they had ever smoked marijuana, and whether they had smoked marijuana in the past 12 months. For those who reported using marijuana in the past 12 months, marijuana frequency was assessed by a follow-up question asking how often participants smoked marijuana. Response options ranged from (1) 1 or 2 times to (6) every day. Respondents who reported no lifetime or past-year marijuana use were coded as 0 .

Third, respondents were asked whether they had ever engaged in sexual intercourse and whether they had engaged in sexual intercourse in the past 12 months. For those who reported past 12 month sexual intercourse, the number of sex partners was assessed through a follow-up question which asked how many sex partners the participant had in the past year. Adolescents who never had sexual intercourse in their lifetime or in the past year were coded as zero.

Fourth, delinquency was measured using 28 questions adapted from the conduct disorder module of the Diagnostic Interview Schedule for ChildrenRevised (DISC-R; Shaffer, Fisher, Lucas, Dulcan, \& Schwab-Stone, 2000). Respondents were asked whether or not they had engaged in 28 different aggressive behaviors in the past 12 months (e.g., held someone up or attacked somebody to steal from them, started a physical fight in which someone was hurt or could have been hurt). The yes responses were summed to create an index of delinquency $(\alpha=.85)$.

Fifth, a scale of peer delinquency was created using nine commonly used items about the respondent's friends. Participants were asked how many of their three best friends smoke cigarettes, drink alcohol, do not get along with their parents, have gotten into trouble at school, have gotten into trouble with the police, are sexually active, have parents who drink or use drugs, have played the 
pass-out/black-out game, and use meth. Response options ranged from (0) no friends to (3) three friends. A composite score was obtained by averaging the nine items $(\alpha=.79)$.

In addition to examining each problem behavior separately, we created an overall problem behavior variable by standardizing each of the five problem behavior indicators and averaging (equal weighting) the scores together $(\alpha=.76)$. Exploratory factor analysis suggested that one factor best accounted for the correlations among the variables (as suggested by problem behavior theory; Jessor \& Jessor, 1977), and each indicator had a factor loading exceeding .45. A confirmatory factor analysis model further suggested that the five indicator latent variable provided a good fit to the data, $\chi^{2}=9.80(5), p=.08$; root mean square error approximation $=.04$; comparative fit index $=.99$.

Anger. Anger was assessed using the Tri-Ethnic Center Anger Scale, which has been previously used and validated among Indigenous adolescent samples (Oetting, Beauvais, \& Edwards, 1988). The adolescents were asked six questions regarding frequency of angry feelings (e.g., how often they feel angry or are quick tempered). Response options ranged from (1) none of the time to (3) most of the time. All six items were averaged to create composite scale scores, with higher values corresponding to higher levels of anger $(\alpha=.82)$.

Perceived racial discrimination. Perceived racial discrimination was assessed using 12 adapted items from the Schedule of Racist Events (Landrine \& Klonoff, 1996). Tribal advisory boards assisted the research team in adapting the original items to be age appropriate and applicable to Indigenous samples. Respondents were asked how often in the past 12 months they perceived discrimination due to their culture (e.g., someone yelled a racial slur at you, someone threatened to harm you physically because you are [cultural group]). Response options ranged from (1) never to (3) many times. Composite scores were obtained by averaging across the items $(\alpha=.86)$.

Controls. Gender was included as a control variable with females coded as one and males coded as zero. Age was also controlled for and was treated as a continuous variable.

\section{Analytic Strategy}

Because the dependent variable — dating violence profiles - is nominal with more than two categories, multinomial logistic regression was used to examine the association of each possible correlate with dating violence profiles. In 
the first set of analyses, unadjusted relative risk ratios (RRR) are presented for each problem behavior indicator, the overall problem behavior construct, anger, perceived discrimination, gender, and age. Although the main focus is on comparing no dating violence with the other three dating violence groups, the results in the tables are presented for all possible contrasts to examine similarities and differences. In the second set of analyses, we used multivariate multinomial logistic regression to examine the joint effects of each hypothesized correlate and control variable. Because the perpetration only group has a small number of cases $(n=30)$, we used the overall problem behavior construct, rather than the individual indicators, to reduce the number of estimated parameters and maximize statistical power.

\section{Results}

\section{Dating Violence Prevalence}

Table 1 presents the descriptive statistics for all variables included in the analyses. Just more than one third (36.5\%) of the adolescents in this sample reported any involvement with physical dating violence (23.6\% reported any perpetration and $31.0 \%$ reported any victimization). Of this group, most reported mutual violence $(18.2 \%)$, rather than perpetration $(5.4 \%)$ or victimization only (12.9\%). We conducted a series of $t$ tests to examine whether overall dating violence perpetration and victimization frequency means differ by profile types. As hypothesized, among those who reported any perpetration, the overall perpetration frequency means were higher in the mutual violence group $(M=4.08, S D=3.38)$ than the perpetration only group $(M=2.57, S D$ $=2.03), t(81)=-3.02, p<.01$. Likewise, for adolescents who reported any dating violence victimization, overall victimization frequency means were higher in the mutual violence group $(M=5.86, S D=5.83)$ than in the victimization only group $(M=2.66, S D=2.32), t(138)=-5.32, p<.001$.

\section{Bivariate Models}

Table 2 presents the unadjusted RRRs predicting membership in the four dating violence profiles. With regard to the problem behavior indicators, the relative risk $(\mathrm{RR})$ of perpetration only, victimization only, and mutual violence versus no dating violence increased as alcohol use, marijuana use, selfreported delinquency, and peer delinquency increased. This pattern held for the number of past-year sex partners for victimization only and mutual violence; however, perpetration only was not significantly different from no dating violence. 
Table 1. Descriptive Statistics for Variables Included in Analyses $(N=551)$.

\begin{tabular}{lrrrrr}
\hline & $M$ & $S D$ & Minimum & Maximum & $\alpha$ \\
\hline Dating violence profiles (\%) & & & & & \\
$\quad$ No dating violence & 63.50 & & & & \\
Perpetration only & 5.40 & & & & \\
Victimization only & 12.90 & & & & \\
$\quad$ Mutual violence & 18.10 & & & & \\
Dating violence & & & & & \\
Any perpetration (any = 1) & 0.24 & & & & \\
Any victimization (any = 1) & 0.31 & & & & \\
Perpetration frequency & 0.88 & 2.21 & 0 & 16.00 & 0.82 \\
Victimization frequency & 1.41 & 3.46 & 0 & 33.00 & 0.89 \\
Problem behaviors & 0.00 & 0.72 & -1.05 & 2.53 & 0.76 \\
$\quad$ Drinking frequency & 1.54 & 1.49 & 0 & 6.00 & - \\
Marijuana frequency & 1.44 & 2.09 & 0 & 6.00 & - \\
Number of sex partners & 1.30 & 1.57 & 0 & 13.00 & - \\
Delinquency & 2.16 & 3.19 & 0 & 21.00 & 0.85 \\
Peer delinquency & 1.34 & 0.65 & 0 & 3.00 & 0.79 \\
Anger & 1.72 & 0.40 & 1 & 3.00 & 0.82 \\
Discrimination & 1.18 & 0.25 & 1 & 2.42 & 0.86 \\
Gender (female = 1) & 0.51 & - & 0 & 1.00 & - \\
Age & 17.24 & 0.88 & 15 & 19.00 & - \\
\hline & & & & & \\
\hline
\end{tabular}

A similar pattern emerged for the remaining variables. As perceived discrimination scores increased, the RR of victimization only and mutual violence rather than no dating violence increased; there was no significant difference between perpetration only and no dating violence. Similarly, the RR of victimization only and mutual violence rather than no dating violence increased as anger scores increased. Anger was not significantly associated with perpetration only. For the two demographic characteristics, the RR of perpetration only and mutual violence rather than no dating violence was higher for females than for males, whereas the RR of victimization only rather than no dating violence was higher for males than for females. Age was not a significant predictor.

\section{Multivariate Models}

Table 3 presents the multivariate multinomial logistic regression models predicting dating violence profiles. The first panel presents correlates of perpetration only, victimization only, and mutual violence, relative to no dating 
Table 2. Unadjusted Relative Risk Ratios Predicting Dating Violence Profile Membership $(N=551)$.

\begin{tabular}{|c|c|c|c|c|c|c|}
\hline & \multicolumn{3}{|c|}{$\begin{array}{c}\text { No dating violence } \\
\text { vs. }\end{array}$} & \multicolumn{2}{|c|}{$\begin{array}{l}\text { Mutual violence } \\
\text { vs. }\end{array}$} & \multirow{2}{*}{$\begin{array}{c}\begin{array}{c}\text { Victimization } \\
\text { only vs. }\end{array} \\
\begin{array}{c}\text { Perpetration } \\
\text { only }\end{array}\end{array}$} \\
\hline & $\begin{array}{c}\text { Perpetration } \\
\text { only }\end{array}$ & $\begin{array}{l}\text { Victimization } \\
\text { only }\end{array}$ & $\begin{array}{c}\text { Mutual } \\
\text { violence }\end{array}$ & $\begin{array}{c}\text { Perpetration } \\
\text { only }\end{array}$ & $\begin{array}{l}\text { Victimization } \\
\text { only }\end{array}$ & \\
\hline $\begin{array}{l}\text { Problem } \\
\text { behaviors }\end{array}$ & $2.83 * * *$ & $2.65^{* * *}$ & $3.60 * * *$ & 0.79 & 0.73 & 1.07 \\
\hline $\begin{array}{l}\text { Drinking } \\
\text { frequency }\end{array}$ & $1.42^{* *}$ & $1.36 * *$ & $1.63 * * *$ & 0.87 & 0.83 & 1.04 \\
\hline $\begin{array}{l}\text { Marijuana } \\
\text { frequency }\end{array}$ & $1.28^{* *}$ & $1.21^{* *}$ & $1.33^{* * *}$ & 0.96 & 0.91 & 1.06 \\
\hline Sex partners & 1.13 & $1.32 * * *$ & $1.29 * * *$ & 0.88 & 1.02 & 0.86 \\
\hline Delinquency & $1.15^{* *}$ & $1.16 * * *$ & $1.21 * * *$ & 0.95 & 0.96 & 0.99 \\
\hline $\begin{array}{l}\text { Delinquent } \\
\text { peers }\end{array}$ & $3.41 * * *$ & $2.40 * * *$ & $3.28 * * *$ & 1.04 & 0.73 & 1.42 \\
\hline Anger & 2.28 & $2.20^{*}$ & $4.01 * * *$ & 0.57 & 0.55 & 1.03 \\
\hline Discrimination & 1.61 & $5.77 * *$ & $11.27^{* * *}$ & $0.14^{*}$ & 0.51 & 0.28 \\
\hline Female & $4.00 * *$ & $0.39 * *$ & $1.70^{*}$ & 2.35 & $0.23 * * *$ & $10.20 * * *$ \\
\hline Age & 0.97 & 0.85 & $1.26+$ & 0.77 & $0.68 *$ & 1.14 \\
\hline
\end{tabular}

${ }^{*} p<.05 ;{ }^{* *} p<.01 ;{ }^{* * *} p<.001$

violence (reference category). Higher levels of problem behaviors increased the RR of perpetration only, victimization only, and mutual violence, versus no dating violence $(\mathrm{RRR}=3.57,2.15$, and 2.97, respectively, $p<.001)$. A oneunit increase in anger scores also increased the RR of mutual violence rather than no dating violence by $97 \%(\mathrm{RRR}=1.97, p<.01)$. Contrary to expectations, anger was not associated with perpetration only or victimization only once other variables were controlled for. Moreover, for each oneunit increase in perceived discrimination, the RR of victimization only and mutual violence rather than no dating violence increased by $211 \%(\mathrm{RRR}=3.11, p<.05)$ and $363 \%(\mathrm{RRR}=4.63, p<.01)$, respectively. Perceived discrimination was not associated with perpetration only. Finally, the $R R$ of perpetration only $(R R R=$ $5.26, p<.01)$ and mutual violence $(\mathrm{RRR}=2.31, p<.01)$ rather than no dating violence was higher for females than males. Likewise, compared with males, females had a lower RR of victimization only, rather than no dating violence ( $\mathrm{RRR}=0.44, p<.01)$.

Although not the primary focus of the analyses, the other contrasts show consistent differences among the dating violence groups by gender. The RR of victimization only rather than mutual violence (reference category) was lower for females than for males $(\mathrm{RRR}=0.19 ; p<.001)$. In addition, the $\mathrm{RR}$ of perpetration only rather than victimization only (reference group) was higher for females than for males $(\mathrm{RRR}=11.87 ; p<.001)$. 
Table 3. Multivariate Multinomial Logistic Regression Predicting Dating Violence Profile Membership $(N=551)$.

\begin{tabular}{|c|c|c|c|c|c|c|}
\hline & \multicolumn{3}{|c|}{$\begin{array}{c}\text { No dating violence } \\
\text { vs. }\end{array}$} & \multicolumn{2}{|c|}{$\begin{array}{c}\text { Mutual violence } \\
\text { vs. }\end{array}$} & \multirow{2}{*}{$\begin{array}{c}\text { Victimization } \\
\text { only vs. } \\
\text { Perpetration } \\
\text { only } \\
\text { RRR } \\
{[95 \% \mathrm{Cl}]}\end{array}$} \\
\hline & $\begin{array}{c}\text { Perpetration } \\
\text { only } \\
\text { RRR } \\
{[95 \% \mathrm{Cl}]}\end{array}$ & $\begin{array}{c}\text { Victimization } \\
\text { only } \\
\text { RRR } \\
{[95 \% \mathrm{Cl}]}\end{array}$ & $\begin{array}{c}\text { Mutual } \\
\text { violence } \\
\text { RRR } \\
{[95 \% \mathrm{Cl}]}\end{array}$ & $\begin{array}{c}\text { Perpetration } \\
\text { only } \\
\text { RRR } \\
{[95 \% \mathrm{Cl}]}\end{array}$ & $\begin{array}{c}\text { Victimization } \\
\text { only } \\
\text { RRR } \\
{[95 \% \mathrm{Cl}]}\end{array}$ & \\
\hline $\begin{array}{l}\text { Problem } \\
\text { behaviors }\end{array}$ & $\begin{array}{c}3.57 * * * \\
{[1.90,6.70]}\end{array}$ & $\begin{array}{c}2.15^{* * *} \\
{[1.43,3.25]}\end{array}$ & $\begin{array}{c}2.97 * * * \\
{[2.01,4.40]}\end{array}$ & $\begin{array}{c}1.20 \\
{[0.62,2.31]}\end{array}$ & $\begin{array}{c}0.72 \\
{[0.45,1.16]}\end{array}$ & $\begin{array}{c}1.66 \\
{[0.83,3.31]}\end{array}$ \\
\hline Anger & $\begin{array}{c}1.17 \\
{[0.41,3.38]}\end{array}$ & $\begin{array}{c}1.23 \\
{[0.60,2.52]}\end{array}$ & $\begin{array}{c}1.97^{*} \\
{[1.03,3.76]}\end{array}$ & $\begin{array}{c}0.60 \\
{[0.20,1.82]}\end{array}$ & $\begin{array}{c}0.62 \\
{[0.27,1.44]}\end{array}$ & $\begin{array}{c}0.96 \\
{[0.29,3.16]}\end{array}$ \\
\hline Discrimination & $\begin{array}{c}0.64 \\
{[0.10,4.26]}\end{array}$ & $\begin{array}{c}3.11^{*} \\
{[1.06,9.07]}\end{array}$ & $\begin{array}{c}4.63^{* *} \\
{[1.81,11.84]}\end{array}$ & $\begin{array}{c}0.14^{*} \\
{[0.02,0.95]}\end{array}$ & $\begin{array}{c}0.67 \\
{[0.21,2.12]}\end{array}$ & $\begin{array}{c}0.21 \\
{[0.03,1.57]}\end{array}$ \\
\hline Female & $\begin{array}{c}5.26 * * \\
{[2.01,13.77]}\end{array}$ & $\begin{array}{c}0.44^{* *} \\
{[0.25,0.79]}\end{array}$ & $\begin{array}{c}2.31 * * \\
{[1.38,3.87]}\end{array}$ & $\begin{array}{c}2.28 \\
{[0.83,6.31]}\end{array}$ & $\begin{array}{c}0.19 * * * \\
{[0.10,0.38]}\end{array}$ & $\begin{array}{c}11.87 * * * \\
{[4.09,34.48]}\end{array}$ \\
\hline Age & $\begin{array}{c}0.95 \\
{[0.61,1.47]}\end{array}$ & $\begin{array}{c}0.76 \\
{[0.56,1.04]}\end{array}$ & $\begin{array}{c}1.17 \\
{[0.88,1.54]}\end{array}$ & $\begin{array}{c}0.81 \\
{[0.51,1.30]}\end{array}$ & $\begin{array}{c}0.65^{*} \\
{[0.45,0.94]}\end{array}$ & $\begin{array}{c}1.24 \\
{[0.75,2.05]}\end{array}$ \\
\hline
\end{tabular}

Pseudo $R^{2}=.12 ; \chi^{2}(15)=137.43 ; p=.000 ; \mathrm{RRR}=$ relative risk ratio, $\mathrm{Cl}=$ confidence interval.

a. $n=350$

b. $n=30$

c. $n=71$

d. $n=100$

${ }^{*} p<.05 ;{ }^{* *} p<.01 ; * * * p<.001$

\section{Discussion}

To our knowledge, this is the first study to examine both the lifetime prevalence and correlates of physical dating violence among North American Indigenous adolescents. Because of the high rates of intimate partner violence among Indigenous adults in the United States (Tjaden \& Thoennes, 2000) and Canada (Perreault, 2011), the current findings provide useful information to inform early prevention and intervention strategies. Likewise, the study adds to the limited body of evidence examining correlates of dating violence profiles among adolescents (e.g., Chiodo et al., 2012; Gray \& Foshee, 1997; Swahn et al., 2010). Given the lack of research among Indigenous youth, this approach allowed us to gain a more holistic descriptive account of dating violence among this population.

\section{Lifetime Prevalence Estimates}

Just under one quarter of the adolescents in this sample reported ever perpetrating dating violence, whereas just under one third of the adolescents 
reported ever being a victim. These lifetime prevalence estimates are similar to those found in previous studies of physical dating violence perpetration (Foshee, 1996; Malik et al., 1997; O'Leary et al., 2008) and victimization (Foshee, 1996; Molidor \& Tolman, 1998; O'Leary et al., 2008). In addition, among those who reported any dating violence, most reported mutual violence, whereas fewer fit into the perpetration only or victimization only groups. These findings mirror a bulk of the research examining the overlap in dating violence perpetration and victimization (Chiodo et al., 2012; Giordano et al., 2010; Gray \& Foshee, 1997; O'Leary et al., 2008; Orpinas et al., 2013; Swahn et al., 2010). We also found that those reporting mutual violence reported more frequent perpetration and victimization experiences. These findings add to the limited research on the context of dating violence profiles (Gray \& Foshee, 1997; Swahn et al., 2010). Moreover, these findings underscore the importance of examining profiles of dating violence, rather than perpetration and victimization in isolation.

Our prevalence estimates for lifetime physical dating violence victimization were higher than those of previous studies of Indigenous youth. For example, our victimization rate was approximately 5 times higher than that found in the Ackard and Neumark-Sztainer (2002) study of high school students in Minnesota. This is likely due to their use of one direct question ("have you ever been the victim of violence on a date?"; p. 459). The current study, by contrast, used a wide range of behaviorally specific measures to capture dating violence experiences. Moreover, it is difficult to compare our lifetime prevalence rates with the past-year estimates reported in the Youth Behavior Risk Surveillance data (i.e., Pavkov et al., 2010; Rutman et al., 2008). Our data do, however, add to the dating violence prevalence estimates of racial and ethnic minority groups, which is currently lacking in the broader literature. Furthermore, these estimates indicate that dating violence is a prevalent issue among this population that warrants further empirical attention.

\section{Correlates of Dating Violence Profiles}

Overall, the clearest pattern to emerge suggests that problem behaviors, anger, and perceived discrimination increase the odds of being both a perpetrator and victim of dating violence (mutual violence). Thus, all of the examined correlates were associated with both victimization and perpetration in the expected ways; however, they were not necessarily associated with perpetration and victimization only, which further underscores the importance of examining dating violence profiles, rather than perpetration and victimization in isolation. 
Indigenous adolescents develop within a unique socio-cultural context, which is shaped by a legacy of historical cultural losses and socio-economic disadvantage (Whitbeck et al., 2014). This context, we argue, shapes exposure to a wide range of proximal risk factors such as substance use, delinquent behavior, negative emotions, and discrimination. These behaviors are likely to cluster together (Jessor \& Jessor, 1977), placing adolescents at risk of additional problem behaviors such as physical dating violence. Our results would appear to fit with this argument and prior research showing alcohol use (Swahn et al., 2006; Temple et al., 2013), marijuana use (Foshee et al., 2010; Gover, 2004), multiple sexual partners (Gover, 2004; O'Donnell et al., 2006), general delinquency (Capaldi et al., 2001; Woodward et al., 2002), and peer delinquency (Capaldi et al., 2001; Howard et al., 2003) as correlates of dating violence victimization and perpetration.

Similarly, these developmental and environmental factors are likely to shape the emotional responses among adolescents, which, in turn, may exacerbate pre-existing risk. The results of this study would appear to support prior research that indicate negative emotionality factors such as anger produce aggressive interactional styles (e.g., mutual violence; Dodge et al., 1990). Furthermore, it suggests that anger is associated with risk of mutual violence over perpetration or victimization only (Wekerle \& Wolfe, 1999).

We also examined an understudied risk factor, perceived racial discrimination, which increased the RR of victimization only and mutual violence, versus no dating violence, but it did not differentiate perpetration only from no dating violence. Given the small number of adolescents who fit into this category, low statistical power may have been an issue. Nevertheless, these results support the small body of prior research on perceived discrimination as a correlate of dating violence perpetration (Reed et al., 2010; Stueve \& O'Donnell, 2008) and victimization (Sanderson et al., 2004; Stueve \& O'Donnell, 2008; Tobler et al., 2013).

Although we have presented the dating violence correlates as theoretically separate from one another, a more complex mediation process may explain these observed findings for perceived racial discrimination. We are inclined to suggest that perceived discrimination may be indirectly associated with dating violence through increases in problem behaviors and negative emotions. Mediation models, however, assume a causal ordering in which the outcome variable precedes the mediation and predictor variables. Because we measured lifetime prevalence, conducting mediation analyses with the data would be of little use, and estimating mediational effect sizes would not be substantively meaningful (see Cole \& Maxwell, 2003). Prior analyses of this data set, however, show a temporal association between perceived discrimination and 
alcohol use (Cheadle \& Whitbeck, 2011), marijuana use (Cheadle \& Sittner Hartshorn, 2012), delinquent peer associations (Whitbeck et al., 2014), anger, and aggressive delinquency (Sittner Hartshorn et al., 2012). Moreover, longitudinal research in the general U.S. population shows a temporal association from problem behaviors (see Vagi et al., 2013 for review) and anger (Foshee et al., 2001) to dating violence. Because of its high magnitude and pernicious effects among racial, ethnic, and cultural minorities (Priest et al., 2013), future research would benefit by examining these possibilities, which can help inform ethno-culturally relevant prevention and intervention programming. Furthermore, it would allow for the theoretical integration of a wider range of risk factors found in the extant adolescent dating violence literature.

Finally, we examined gender in our analyses. Females had higher odds of being in the perpetration only or mutual violence groups. Males, on the other hand, had higher odds of being in the victimization only group. These findings mirror prior research which shows females are more likely to perpetrate and males are more likely to be victimized (Foshee, 1996; Giordano et al., 2010; O'Leary et al., 2008). Given the variability in the literature and the current data, we also examined the possibility of moderating effects by gender (results available on request). None of these gender interactions were statistically significant suggesting that the hypothesized correlates of dating violence profile membership do not vary as a function of gender. More research is needed to further disentangle this relationship and examine possible etiological factors for why females are more likely to report perpetration, whereas males are more likely to report victimization among Indigenous and non- Indigenous populations.

\section{Limitations}

Several limitations warrant discussion. First, given cultural and geographic heterogeneity, the results of this study may not be generalizable to other Indigenous cultural groups in the United States and Canada. Intimate partner violence rates likely vary by regional tribal community (Yuan, Koss, Polacca, \& Goldman, 2006). Moreover, the reservations/reserves in this study are mainly rural, and the findings may not be applicable to urban Indigenous adolescents, even within the same cultural group. We believe that more research is needed to better understand dating violence among this vulnerable and understudied population.

Second, dating violence was measured as lifetime experiences and was not assessed until the seventh year of the study; thus, we are limited in establishing temporal ordering. Identifying causal predictors of dating violence is the ideal standard for the formation of prevention and intervention initiatives (Vagi 
et al., 2013). Similarly, each of the correlates examined may potentially operate as both risk factors and consequences of dating violence. Future studies on dating violence among Indigenous youth would benefit from longitudinal designs in which the onset of dating violence and risk factors/ consequences can fully be established.

Third, we are unable to establish whether dating violence is unidirectional or bidirectional (reciprocal) within dating relationships. Instead, we are only able to assess whether adolescents had ever perpetrated dating violence or had been victimized by a dating partner. It is plausible that adolescents may be a victim in one relationship and a perpetrator in another (and vice versa; e.g., Cui et al., 2013).

\section{Conclusion}

Despite these limitations, the current study provides preliminary and useful information on physical dating violence among an understudied population. The results suggest possible areas for prevention and intervention in general and among Indigenous groups specifically. Given the robust links between problem behaviors and dating violence risk, programs targeting multiple domains of adolescent risk and violence may be most efficacious and efficient in addressing a wide variety of health risk behaviors (Vagi et al., 2013). The correlation between perceived discrimination and dating violence is particularly noteworthy. It points to the importance of culturally relevant risk factors and the need to adapt prevention responses to the community and cultural contexts in which they are embedded. Interventions among Indigenous youth should be developed or adapted with community input (Crooks, 2008), actively engage youth in the process (Crooks, Chiodo, Thomas, \& Hughes, 2010), and take into account the unique contexts in which Indigenous adolescent development occurs (Whitbeck et al., 2014).

Funding - This research was supported by grants from the National Institute on Drug Abuse (DA13580), National Institute of Mental Health (MH67281), and National Institute on Alcohol Abuse and Alcoholism (1R01AA020299-01A1) awarded to L. Whitbeck. The authors have no potential conflicts of interest with respect to the research, authorship, and publication of this article. 


\section{References}

Ackard, D., \& Neumark-Sztainer, D. (2002). Date violence and date rape among adolescents: Associations with disordered eating behaviors and psychological health. Child Abuse \& Neglect, 26, 455-473. doi: 10.1016/S0145-2134(02)00322-8

Agnew, R. (2001). Building on the foundation of general strain theory: Specifying the types of strain most likely to lead to crime and delinquency. Journal of Research in Crime \& Delinquency, 38, 319-361. doi: 10.1177/0022427801038004001

Capaldi, D. M., Dishion, T. J., Stoolmiller, M., \& Yoerger, K. (2001). Aggression toward female partners by at-risk young men: The contribution of male adolescent friendships. Developmental Psychology, 37, 61-73. doi: 10.1037//0012-1649.37.1.61

Cheadle, J. E., \& Sittner Hartshorn, K. J. (2012). Marijuana use development over the course of adolescence among North American indigenous youth. Social Science Research, 41, 1227-1240. doi: 10.1016/j.ssresearch.2012.03.015

Cheadle, J. E., \& Whitbeck, L. B. (2011). Alcohol use trajectories and problem drinking over the course of adolescence: A study of North American Indigenous youth and their caretakers. Journal of Health and Social Behavior, 52, 228-245. doi: $10.1177 / 0022146510393973$

Chiodo, D., Crooks, C. V., Wolfe, D. A., McIsaac, C., Hughes, R., \& Jaffe, P. G. (2012). Longitudinal prediction and concurrent functioning of adolescent girls demonstrating various profiles of dating violence and victimization. Prevention Science, 13, 350359. doi: $10.1007 / \mathrm{s} 11121-011-0236-3$

Clarey, A., Hokoda, A., \& Ulloa, E. (2010). Anger control and acceptance of violence as mediators in the relationship between exposure to interpersonal conflict and dating violence perpetration in Mexican adolescents. Journal of Family Violence, 25, 619625. doi: 10.1007/s10896-010-9315-7

Cleveland, H., Herrera, V., \& Stuewig, J. (2003). Abusive males and abused females in adolescent relationships: Risk factor similarity and dissimilarity and the role of relationship seriousness. Journal of Family Violence, 18, 325-339. doi: 10.1023/A:1026297515314

Cole, D. A., \& Maxwell, S. E. (2003). Testing mediational models with longitudinal data: Questions and tips in the use of structural equation modeling. Journal of $A b$ normal Psychology, 112, 558-577. doi: 10.1037/0021-843X.112.4.558

Crooks, C. V. (2008). Engaging Aboriginal youth in school-based violence prevention: A comprehensive evaluation perspective. In D. Pepler \& W. Craig (Eds.), Understanding and addressing bullying: An international perspective (pp. 198-214). Bloomington, IN: AuthorHouse.

Crooks, C. V., Chiodo, D., Thomas, D., \& Hughes, R. (2010). Strengths-based programming for first nations youth in schools: Building engagement through healthy relationships and leadership skills. International Journal of Mental Health and Addiction, 8, 160-173. doi: 10.1007/s11469-009-9242-0

Cui, M., Ueno, K., Gordon, M., \& Fincham, F. D. (2013). The continuation of intimate partner violence from adolescence to young adulthood. Journal of Marriage and Family, 75, 300-313. doi: 10.1111/jomf.12016

Dodge, K. A., Price, J. M., Coie, J. D., \& Christopoulos, C. (1990). On the development of aggressive dyadic relationships in boys' peer groups. Human Development, 33, 260-270. doi: 10.1159/000276523 
Foshee, V. A. (1996). Gender differences in adolescent dating abuse prevalence, types and injuries. Health Education Research, 11, 275-286. doi: 10.1093/her/11.3.275-a

Foshee, V. A., Linder, F., MacDougall, J. E., \& Bangdiwala, S. (2001). Gender differences in the longitudinal predictors of adolescent dating violence. Prevention Medicine, 32, 128-141. doi: 10.1006/pmed.2000.0793

Foshee, V., McNaughton Reyes, H., \& Ennett, S. (2010). Examination of sex and race differences in longitudinal predictors of the initiation of adolescent dating violence perpetration. Journal of Aggression, Maltreatment \& Trauma, 19, 492-516. doi: $10.1080 / 10926771.2010 .495032$

Giordano, P. C., Soto, D. A., Manning, W. D., \& Longmore, M. A. (2010). The characteristics of romantic relationships associated with teen dating violence. Social Science Research, 39, 863-874. doi: 10.1016/j.ssresearch.2010.03.009

Gorman-Smith, D., Tolan, P., Sheidow, A., \& Henry, D. (2001). Partner violence and street violence among urban adolescents: Do the same family factors relate? Journal of Research on Adolescence, 11, 273-295. doi: 10.1111/1532-7795.00013

Gover, A. R. (2004). Risky lifestyles and dating violence: A theoretical test of violent victimization. Journal of Criminal Justice, 32, 171-180. doi: 10.1016/j. jcrimjus.2003.12.007

Gray, H. M., \& Foshee, V. (1997). Adolescent dating violence: Differences between one-sided and mutually violent profiles. Journal of Interpersonal Violence, 12, 126141. doi: $10.1177 / 088626097012001008$

Howard, D., Qiu, Y., \& Boekeloo, B. (2003). Personal and social contextual correlates of adolescent dating violence. Journal of Adolescent Health, 33, 9-17. doi: 10.1016/ S1054-139X(03)00061-2

Jessor, R., \& Jessor, S. (1977). Problem behavior and psychosocial development: A longitudinal study. New York, NY: Academic Press.

Landrine, H., \& Klonoff, E. A. (1996). The schedule of racist events: A measure of racial discrimination and a study of its negative physical and mental health consequences. Journal of Black Psychology, 22, 144-168. doi: 10.1177/00957984960222002

Malik, S., Sorenson, S. B., \& Aneshensel, C. S. (1997). Community and dating violence among adolescents: Perpetration and victimization. Journal of Adolescent Health, 21, 291-302. doi: 10.1016/S1054-139X(97)00143-2

McNulty, T., \& Bellair, P. (2003). Explaining racial and ethnic differences in serious adolescent violent behavior. Criminology, 41, 709-747. doi: 10.1111/j.1745-9125.2003. tb01002.x

Melander, L., Sittner Hartshorn, K., \& Whitbeck, L. (2013). Correlates of bullying behaviors among a sample of North American Indigenous adolescents. Journal of Adolescence, 36, 675-684. doi: 10.1016/j.adolescence.2013.05.003

Molidor, C., \& Tolman, R. (1998). Gender and contextual factors in adolescent dating violence. Violence Against Women, 4, 180-194. doi: 10.1177/1077801298004002004

O’Donnell, L., Stueve, A., Myint-U, A., Duran, R., Agronick, G., \& Wilson-Simmons, R. (2006). Middle school aggression and subsequent intimate partner violence. Journal of Youth and Adolescence, 35, 693-703. doi: 10.1007/s10964-006-9086-x

Oetting, E., Beauvais, F., \& Edwards, R. (1988). Alcohol and Indian youth: Social and psychological correlates and prevention. Journal of Drug Issues, 18, 87-101. 
O'Leary, K. D., Smith Slep, A. M., Avery-Leaf, S., \& Cascardi, M. (2008). Gender differences in dating aggression among multiethnic high school students. Journal of Adolescent Health, 42, 473-479. doi: 10.1016/j.jadohealth.2007.09.012

Orpinas, P., Hsieh, H. L., Song, X., Holland, K., \& Nahapetyan, L. (2013). Trajectories of physical dating violence from middle to high school: Association with relationship quality and acceptability of aggression. Journal of Youth and Adolescence, 42, 551-565. doi: 10.1007/s10964-012-9881-5

Pavkov, T. W., Travis, L., Fox, K. A., King, C. B., \& Cross, T. L. (2010). Tribal youth victimization and delinquency: Analysis of youth risk behavior surveillance survey data. Cultural Diversity \& Ethnic Minority Psychology, 16, 123-134. doi: 10.1037/a0018664

Perreault, S. (2011). Violent victimization of aboriginal people in the Canadian provinces, 2009. Ottawa, Ontario, Canada: Statistics Canada.

Priest, N., Paradies, Y., Trenerry, B., Truong, M., Karlsen, S., \& Kelley, Y. (2013). A systematic review of studies examining the relationship between reported racism and health and wellbeing for children and young people. Social Science \& Medicine, 95, 115-127. doi: 10.1016/j.socscimed.2012.11.031

Reed, E., Silverman, J. G., Ickovics, J. R., Gupta, J., Welles, S. L., Santana, M. C., \& Raj, A. (2010). Experiences of racial discrimination and relation to violence perpetration and gang involvement among a sample of urban African American men. Journal of Immigrant and Minority Health, 12, 319-326. doi: 10.1007/s10903-008-9159-x

Reingle, J. M., Staras, S. A., Jennings, W. G., Branchini, J., \& Maldonado-Molina, M. M. (2012). The relationship between marijuana use and intimate partner violence in a nationally representative, longitudinal sample. Journal of Interpersonal Violence, 27, 1562-1578. doi: 10.1177/0886260511425787

Rhule-Louie, D. M., \& McMahon, R. J. (2007). Problem behavior and romantic relationships: Assortative mating, behavior contagion, and desistance. Clinical Child and Family Psychology Review, 10, 53-100. doi: 10.1007/s10567-006-0016-y

Rutman, S., Park, A., Castor, M., Taualii, M., \& Forquera, R. (2008). Urban American Indian and Alaska native youth: Youth risk behavior survey 1997-2003. Maternal and Child Health Journal, 12, 76-81. doi: 10.1007/s10995-008-0351-3

Sanderson, M., Coker, A. L., Roberts, R. E., Tortolero, S. R., \& Reininger, B. M. (2004). Acculturation, ethnic identity, and dating violence among Latino ninth-grade students. Preventive Medicine, 39, 373-383. doi: 10.1016/j.ypmed.2004.01.034

Shaffer, D., Fisher, P., Lucas, C. P., Dulcan, M. K., \& Schwab-Stone, M. E. (2000). NIMH Diagnostic Interview Schedule for Children Version IV (NIMH DISC-IV): Description, differences from previous versions, and reliability of some common diagnoses. Journal of the American Academy of Child \& Adolescent Psychiatry, 39, 2838. doi: 10.1097/00004583-200001000-00014

Sittner Hartshorn, K. J., Whitbeck, L. B., \& Hoyt, D. R. (2012). Exploring the relationships of perceived discrimination, anger, and aggression among North American indigenous adolescents. Society and Mental Health, 2, 53-67. doi: $10.1177 / 2156869312441185$

Stueve, A., \& O'Donnell, L. (2008). Urban young women's experiences of discrimination and community violence and intimate partner violence. Journal of Urban Health, 85, 386-401. doi: 10.1007/s11524-008-9265-z 
Swahn, M. H., Alemdar, M., \& Whitaker, D. J. (2010). Nonreciprocal and reciprocal dating violence and injury occurrence among urban youth. Western Journal of Emergency Medicine, 11, 264-268.

Swahn, M. H., Bossarte, R. M., \& Sullivent, E. E. (2006). Age of alcohol use initiation, suicidal behavior, and peer and dating violence victimization and perpetration among high-risk, seventh-grade adolescents. Pediatrics, 121, 297-305. doi: 10.1542/ peds.2006-2348

Temple, J., Shorey, R., Fite, P., Stuart, G., \& Le, V. (2013). Substance use as a longitudinal predictor of the perpetration of teen dating violence. Journal of Youth and Adolescence, 42, 596-606. doi: 10.1007/s10964-012-9877-1

Tjaden, P. G., \& Thoennes, N. (2000). Extent, nature, and consequences of intimate partner violence. Washington, DC: National Institute of Justice.

Tobler, A. L., Maldonado-Molina, M. M., Staras, S. A., O’Mara, R. J., Livingston, M. D., \& Komro, K. A. (2013). Perceived racial/ethnic discrimination, problem behaviors, and mental health among minority urban youth. Ethnicity \& Health, 18, 337349. doi: 10.1080/13557858.2012.730609

Vagi, K. J., Rothman, E. F., Latzman, N. E., Tharp, A. T., Hall, D. M., \& Breiding, M. J. (2013). Beyond correlates: A review of risk and protective factors for adolescent dating violence perpetration. Journal of Youth and Adolescence, 42, 633-649. doi: 10.1007/s10964-013-9907-7

Valois, R. F., Oeltmann, J. E., Waller, J., \& Hussey, J. R. (1999). Relationship between number of sexual intercourse partners and selected health risk behaviors among public high school adolescents. Journal of Adolescent Health, 25, 328-335. doi: 10.1016/ S1054-139X(99)00051-8

Wallace, J., Bachman, J., O’Malley, P., Johnston, L., Schulenberg, J., \& Cooper, C. (2002). Tobacco, alcohol, and illicit drug use: Racial and ethnic difference among U.S. high school seniors, 1976-2000. Public Health Reports, 117(Suppl.1), S67-S75.

Wekerle, C., \& Wolfe, D. (1999). Dating violence in mid-adolescence: Theory, significance, and emerging prevention initiatives. Clinical Psychology Review, 19, 435-456. doi: 10.1016/S0272-7358(98)00091-9

Whitbeck, L., Sittner Hartshorn, K., \& Walls, M. (2014). Indigenous adolescent development: Psychological, social and historical contexts. New York, NY: Psychology Press.

Wolf, K., \& Foshee, V. (2003). Family violence, anger expression styles, and adolescent dating violence. Journal of Family Violence, 18, 309-316. doi: 10.1023/A:1026237914406

Woodward, L. J., Fergusson, D. M., \& Horwood, L. J. (2002). Romantic relationships of young people with childhood and adolescent onset antisocial behavior problems. Journal of Abnormal Child Psychology, 30, 231-243. doi: 10.1023/A:1015150728887

Yuan, N. P., Koss, M. P., Polacca, M., \& Goldman, D. (2006). Risk factors for physical assault and rape among six Native American tribes. Journal of Interpersonal Violence, 21, 1566-1590. doi: 10.1177/0886260506294239 


\section{The Authors}

Dane S. Hautala is a doctoral student in sociology at the University of Nebraska-Lincoln. His research focuses on stress, mental health, and delinquency among adolescents, with a particular focus on North American Indigenous populations.

Kelley J. Sittner Hartshorn, PhD, is an assistant professor in the Department of Sociology at Oklahoma State University. She received her PhD in sociology in 2011 from the University of Nebraska-Lincoln. Her research focuses on antisocial behavior, mental health, and substance use among adolescents.

Brian Armenta, $\mathrm{PhD}$, is a postdoctoral research associate in the Department of Sociology at the University of Nebraska-Lincoln. He received his $\mathrm{PhD}$ in psychology in 2013 from the University of Nebraska-Lincoln. His research focuses on individual, interpersonal, and contextual factors that affect the physical and mental health of ethnic minority populations.

Les Whitbeck, $\mathrm{PhD}$, is Professor Emeritus in the Department of Sociology at the University of Nebraska-Lincoln. He was the principal investigator for the Midwest Longitudinal Study of Homeless Adolescents. In addition, he is principal investigator for an 8-year diagnostic study of American Indian children aged 10 to 12 years. He has authored or coauthored two books on homeless adolescents, one book on Indigenous adolescent development, and more than 130 refereed journal articles. He received the 2007 Community, Culture, and Prevention Science Award from the Society for Prevention Research. 